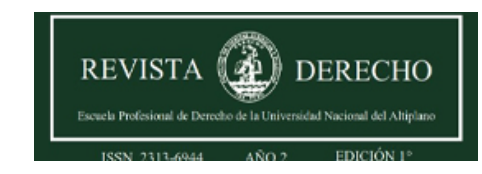

Revista de Derecho

ISSN: 2313-6944

ISSN: 2707-9651

revistaderecho@unap.edu.pe

Universidad Nacional del Altiplano

Perú

\title{
Entre el proceso inmediato y el derecho a la defensa eficaz: Garantías constitucionales y anotaciones previas sobre el plazo razonable
}

\author{
Guzman Arpasi, Rodrigo \\ sobre el plazo razonable \\ Revista de Derecho, vol. 6, núm. 2, 2021 \\ Universidad Nacional del Altiplano, Perú \\ Disponible en: https://www.redalyc.org/articulo.oa?id=671870938012 \\ DOI: https://doi.org/10.47712/rd.2021.v6i2.119
}

Entre el proceso inmediato y el derecho a la defensa eficaz: Garantías constitucionales y anotaciones previas

\section{(c) (7)}

Esta obra está bajo una Licencia Creative Commons Atribución 4.0 Internacional. 
Artículos de investigaciones realizadas por estudiantes con docentes

\section{Entre el proceso inmediato y el derecho a la defensa eficaz: Garantías constitucionales y anotaciones previas sobre el plazo razonable}

Between the immediate process and the right to effective defense: Constitutional guarantees and prior annotations on the reasonable time

Rodrigo Guzman Arpasi

Universidad Nacional del Altiplano, Perú

DOI: https://doi.org/10.47712/rd.2021.v6i2.119

Redalyc: https://www.redalyc.org/articulo.oa?

$\mathrm{id}=671870938012$

Recepción: 12 Febrero 2021

Aprobación: 30 Julio 2021

Publicación: 05 Agosto 2021

\section{RESUMEN:}

Este artículo desarrolla el proceso inmediato como referencia de simplificación y celeridad procesal, el mismo que ha sido elaborado bajo el aporte de numerosos autores en materia procesal penal. Siguiendo una óptica pragmática y doctrinaria; se ha tomado como matriz principal, el desarrollo teórico realizado por Alonso Peña Cabrera Freyre frente a las aclaraciones y reflexiones brindadas por César Nakazaki Servigón. Desde los antecedentes del proceso inmediato, su evolución en el ordenamiento peruano, su aplicación y resolución procesal, hasta su naturaleza jurídica, el derecho a la defensa eficaz y el plazo razonable. Finalmente, se ha desarrollado un conjunto de conclusiones que configuran el objetivo de este trabajo, el mismo que obedece a la revaloración de los presupuestos materiales y los supuestos legales de aplicación por parte del Ministerio Público en las nuevas reglas y garantías que recoge el Nuevo Código Procesal Penal del año 2004.

Palabras Clave: Derecho procesal penal, Proceso inmediato, Debido proceso, Derecho a la defensa eficaz, Plazo razonable y Garantías constitucionales.

\section{Abstract:}

This article develops the immediate process as a reference for procedural simplification and speed, the same that has been prepared with the contribution of numerous authors in criminal procedural matters. Following a pragmatic and doctrinal perspective; The main matrix has been taken as the theoretical development carried out by Alonso Peña Cabrera Freyre against the clarifications and reflections provided by César Nakazaki Servigón. From the antecedents of the immediate process, its evolution in the Peruvian legal system, its application and procedural resolution, to its legal nature, the right to effective defense and the reasonable period of time. Finally, a set of conclusions has been developed that configure the objective of this work, the same one that obeys the reassessment of the material budgets and the legal assumptions of application by the Public Ministry in the new rules and guarantees that the New Code includes Criminal Procedure of the year 2004.

KEYWORDS: Criminal procedural law, Immediate process, Due process, Right to effective defense, Reasonable term and Constitutional guarantees.

\section{INTRODUCCIÓN}

Cuando empezamos a estudiar Derecho Procesal General, o en otros casos, la Teoría General del Proceso, entendemos que uno de los principales objetivos que tiene la asignatura; es de valorar y comprender la importancia de los Principios Procesales, los cuales se configuran como aquellas reglas o conceptos que van a ser aplicables a todos los procesos judiciales. O por lo menos, en su mayoría.

Dentro de aquellos principios, el que respecta a "la igualdad ante la ley" y "la similitud de condiciones entre las partes", son los que debemos analizar, con un mayor énfasis y cuidado. Puesto que no debemos olvidar, sobre todo cuando hablamos de Derecho Procesal Penal, que el imputado cuenta con una facultad especial; la cual todos conocemos como la "Presunción de Inocencia". Este principio, exclusivo del Proceso Penal, representa la desigualdad -llamémosle favorable-, que cuentan todas aquellas personas que atraviesan 
un proceso penal contra el estado. Es justamente aquí donde se inclina la balanza a favor del imputado, y con justa razón, ya que hablamos de penas que acarrean y constituyen la privación de la libertad dependiendo del tipo penal configurable.

Inicio con este punto para poder adentrarnos al tema que desarrollaremos en este artículo, el cual tiene como objetivo principal; comprender uno de los procesos especiales que está recogido dentro del Nuevo Código Procesal Penal del año 2004, específicamente; el Proceso Inmediato.

A continuación, abordaremos sus antecedentes en el antiguo Código de Procedimientos Penales de 1940 y su evolución con el actual código, seguido también, de la reforma que sufrió con el Decreto Legislativo No 1194 a través de la Ley No 30336.

Como ya todos sabemos, el Nuevo Código Procesal Penal del año 2004 -que en realidad entró en vigencia en el año 2006-, regula un proceso penal común con tres etapas claras y definidas: la investigación preparatoria, una etapa intermedia y, por último; la etapa de juicio oral. Pero, además, a la par de ese proceso común, nuestro código regula, a su vez, una serie de procesos especiales, cada uno de ellos con determinadas reglas y supuestos para su aplicación (Salas, 2011). Entre estos procesos especiales, podemos encontrar ejemplos como: la terminación anticipada, el proceso de colaboración eficaz, el proceso de seguridad, entre otros.

De todos esos procesos especiales que hemos mencionado, el que desarrollaremos a continuación es el proceso inmediato, el cual tiene una idea de "procedimiento célere" y está regulado en la primera sección del libro quinto del Nuevo Código Procesal Penal. Este proceso, entre todas sus características, lo que busca es simplificar etapas y aligerar el proceso sólo en determinados casos. Hasta ahí ya tenemos una pequeña idea sobre la lógica en la que se encuentra este proceso especial; el cual busca alcanzar, básicamente la aceleración de un proceso que, en respectiva, tendrá ciertas características especiales. Pero, ¿de dónde nace esta idea de "celeridad procesal" ?, ¿ya había estado presente antes en el legislador peruano?, ¿o es, quizás, algo que nuestro sistema procesal recién reconoce?

El proceso inmediato tiene una relevancia originaria en el ordenamiento italiano del año 1988, el mismo que regulaba el «giudizzio direttissimo» y el «giudizzio inmediato», que en español significaría: “yo juzgo de manera directa" y “yo juzgo de manera inmediata”. De acuerdo con Araya (2016), estas figuras se utilizaban para ahorrar etapas de investigación y para atribuirle la responsabilidad al imputado cuando existía prueba evidente.

En el caso del Perú, podríamos deducir que sucedía algo similar, pero con otro nombre y bajo otro tipo de requisitos. Recordemos, pues, que el antiguo Código de Procedimientos Penales de 1940, regulaba un "proceso ordinario", que, de la misma forma que el actual proceso común, contaba con diferentes etapas; empezando por una Investigación Preliminar, la cual estaba a cargo del fiscal provincial, seguido de ello, una "Audiencia de imputación de cargos". Luego con una "Etapa de Instrucción”, que estaba dirigido por el juez penal. Después, llegaba a una sala penal que corría traslado a un fiscal superior y este mismo, era el que recién formulaba la acusación, para finalmente así, arrancar el juicio por patrocinio de esta misma sala.

Este era el proceso penal ordinario que regulaba el antiguo código de 1940, el cual, dicho sea de paso, aún sigue vigente en algunos distritos judiciales en Lima.

Como podemos observar en el párrafo anterior, el proceso penal ordinario del antiguo código era muy extenso, teniendo en cuenta que participaban dos fiscales y cuatro magistrados en una primera instancia, sin mencionar, además, lo que sucedía cuando se presentaba un "Recurso de nulidad", el cual era la manera para poder ejercer el derecho que tenía el imputado a una segunda instancia en esos tiempos.

Ahora bien, en líneas atrás mencionaba que en el Perú ocurría algo similar a lo que Italia se entendía como el «giudizzio inmediato». Y es que el legislador, asumo yo, entendió que el proceso penal ordinario necesitaba un tipo de proceso especial que tenga esa característica de celeridad procesal. Es justamente ahí donde encontramos al "proceso sumario", que vendría a ser el -antecedente procesal- del proceso inmediato en el antiguo código, con la misma idea y lógica de obviar etapas pero que, a su vez, se va a diferenciar 
en la forma de aplicarse; mientras que el proceso sumario estaba dedicado para algunos delitos, el proceso inmediato tendrá sus propios supuestos de aplicación.

De tal manera que, en un proceso sumario; después de la investigación preliminar, se pasaba a ala etapa de instrucción y ahí mismo se emitía sentencia. Un proceso mucho más rápido y con sólo dos actores; un fiscal provincial y un juez penal.

Hasta este punto, hemos comenzado con una pequeña aproximación sobre los procesos especiales, y he visto por conveniente hacer este recuento y comparación con el código de 1940 para mostrarle al lector que la idea de resumir, acortar y darle rapidez o celeridad al proceso, no es algo nuevo, ya que viene sucediendo desde hace mucho tiempo. Y que el moderno legislador del nuevo código del 2004 ha heredado con las experiencias del antiguo proceso sumario de 1940.

Después de haber entrado en este contexto acerca de los procesos especiales, vamos a desarrollar y enfocarnos en el proceso inmediato, tomando en cuenta los alcances de diversos autores sobre su sentido y naturaleza jurídica.

\section{El Proceso Inmediato}

Se trata de un proceso especial que es llevado a cabo cuando las circunstancias permitan que se pueda acortar o no exista la necesidad de llevar a cabo algunas etapas del proceso común; las cuales son la investigación preparatoria formalizada y la etapa intermedia. Es decir, busca la simplificación y celeridad de las etapas del proceso común en aquellos casos donde el Ministerio Público no requiera realizar mayores investigaciones. Talavera (2010) afirma que: "Los procedimientos especiales, en cambio, están previstos para delitos muy concretos o circunstancias específicas de especial relevancia procesal, configurándose modelos de procedimiento muy propios, por entero alejados del modelo originario" (p. 97).

Nótese que el profesor Talavera no habla de un proceso especial, sino de "procedimientos especiales", ¿existe alguna diferencia que debamos considerar?

Para abordar este punto, tomaremos en cuenta las aclaraciones del profesor Alonso Peña Cabrera.

Cuando estamos frente a un proceso, vamos a ver un conjunto de actos interconectados e intercalados entre sí, que están reglados a cargo de una autoridad jurisdiccional competente, que, a su vez, está destinada a emitir una decisión firme y eficaz. En cambio, el procedimiento, implica una secuencia de actos para un fin específico determinado (Peña Cabrera, 2019, pp. 33-34).

Entonces, podríamos hablar de una relación de inducción, porque cuando hablamos del proceso, podemos incluír varios procedimientos. Basándonos en esta aclaración que nos da el profesor Peña Cabrera, entenderemos que el proceso penal también posee sus propios procedimientos, como, por ejemplo; el procedimiento cautelar, los procedimientos impugnatorios o incluso los procedimientos que abarcan los mecanismos de la defensa.

¿Por qué es importante rescatar esta aclaración? Porque es a raíz de las bases que se sientan sobre el proceso, donde podremos entender que el tratamiento de casos dentro de los cuales están establecidos en el nuevo código procesal penal para el proceso común, no es el mismo para aquellos que regula el proceso inmediato.

\section{Supuestos Legales de Procedencia}

Según el artículo $446^{\circ}$ del código procesal penal, este proceso puede ser solicitado por el fiscal cuando existan tres supuestos de procedencia y dos tipos penales concretos:

- Flagrancia delictiva

- Confesión sincera

- Evidencia en virtud a los elementos de convicción con los que se cuente 
- Omisión a la asistencia familiar y conducción en estado de ebriedad o drogadicción

Recordemos que en el inicio mencioné que, para diferenciar entre un proceso sumario y un proceso inmediato, teníamos que fijarnos en sus requisitos para su aplicación; mientras que el proceso sumario estaba destinado para regular algunos delitos, el proceso inmediato estaba pensado bajo supuestos legales de procedencia.

Sin embargo, ahora podemos ver que, a parte de los tres supuestos de procedencia, también se han incorporado dos tipos penales; la omisión a la asistencia familiar y la conducción en estado de ebriedad o drogadicción. ¿Es lógico incluir estos dos delitos en un proceso inmediato?, claro que sí, porque mantienen, básicamente, la misma lógica que los tres supuestos anteriores: la rapidez o celeridad del proceso.

Empero y, como veremos a continuación sobre los presupuestos procesales; lo anterior no significa que el proceso inmediato sea auto - aplicable. También existen presupuestos materiales que determinarán la viabilidad del proceso inmediato.

En los casos de flagrancia delictiva, el fiscal puede solicitar este proceso después de que culmine el plazo de la detención policial. En cuanto a los demás supuestos, el código menciona que puede solicitarse cuando se hayan culminado con las diligencias preliminares o antes de los treinta días de haber formalizado la investigación preparatoria.

Sumado a ello, pondré sobre el tapete del debate lo que ha generado el Decreto Legislativo $N^{\circ} 1194$, el cual pretende que ya no hablemos y discutamos una decisión, sino, muy por el contrario, de una obligación. Recordemos que el código procesal penal establecía que el Ministerio Público tenía la facultad discrecional para incoar o no un proceso inmediato. Ahora, con la modificación del artículo $446^{\circ}$ por parte del Decreto Legislativo $\mathrm{N}^{\circ} 1194$, esta decisión ya no corresponde a una facultad que tenía el fiscal, sino, por el contrario, ahora obedece a una obligación bajo responsabilidad, salvo en los casos de complejidad, -que también estarán desarrollados más abajo, en los presupuestos materiales- donde existía una exoneración de incoación.

$\mathrm{Al}$ respecto, de manera enfática, Peña Cabrera (2017) menciona que resulta inaceptable la idea de sujetar la actuación del Ministerio Público a las intenciones de otros poderes, olvidando así la independencia y autonomía que la propia Constitución le confiere como un organismo autónomo para ejercer la titularidad de la acción penal. El fiscal no puede convertirse en un ciego operador de la ley, sino, por el contrario, tiene que tener una característica visionaria de la misma, en consecuencia, lo que estipula y demanda el Decreto Legislativo No 1194 acarrea la vulneración de la autonomía del ministerio público en la investigación criminal.

\section{Presupuestos Materiales de Aplicación}

Después de mencionar la grave afectación que sufrió la autonomía del Ministerio Público por el Decreto Legislativo $N^{o} 1194$, es preciso señalar la respuesta que manifestó la Fiscalía de la Nación cuando aprobó la Directiva No 005 - 2015 - MP - FN “Actuación Fiscal en casos de detención en flagrancia delictiva, proceso inmediato y requerimiento de prisión preventiva”, el cual menciona que el fiscal debe incoar prisión preventiva siempre y cuando cuente con las evidencias de incriminación suficientes como para acreditar la materialidad del hecho punible. De lo contrario, a pesar de que nos encontremos frente a un escenario de flagrancia delictiva, deberá proseguir con la investigación.

Con este último párrafo deducimos que el Proceso inmediato responde a dos motivos; primero a los supuestos legales de procedencia, los cuales hemos desarrollado líneas atrás. Y, segundo, a los presupuestos materiales de aplicación. Es muy importante que tengamos en cuenta esta premisa, porque puede que se presenten situaciones en donde se evidencien supuesto legales de aplicación, pero no existan presupuestos materiales. En este tipo de casos, el proceso inmediato se vuelve inadmisible.

De acuerdo con el Acuerdo Plenario Extraordinario 2-2016/CIJ-116 [1], tenemos dos presupuestos materiales; la evidencia delictiva y la ausencia de complejidad. 
Sobre la evidencia delictiva; debemos entenderla simplemente como la "certeza que tenemos sobre el hecho", conjuntamente con la seguridad que debe existir en cuanto a la responsabilidad del sujeto sobre el hecho delictivo.

Respecto a la ausencia de complejidad, desarrollaremos los siguientes: Supuestos de complejidad previstos en el artículo 342, inciso 3 del CPP[2].

- Los mismos que refieren al requerimiento de actuación de una significativa cantidad de actos de investigación, comprender la investigación de numerosos delitos, involucrar una cantidad significativa de imputados o agraviados, investigar delitos que han sido perpetrados por personas integrantes a bandas $\mathrm{u}$ organizaciones criminales, que se demande la realización de pruebas periciales que requieran de análisis técnicos y, por último, que se requiera revisar la participación, gestión de personas jurídicas o entidades del estado.

- Hechos complejos.

- Existan motivos para dudar de la fiabilidad, legalidad o la suficiencia de los elementos de convicción por parte del Ministerio Público.

- Razones de distancia, de remisión de muestras y su análisis.

- Saturación de servicios periciales.

\section{Resolución Procesal}

En cuanto a su resolución, existe una primera audiencia en la que se determina su procedencia, del mismo modo, es en esta misma audiencia en donde podrían aplicarse algunos criterios; como el principio de oportunidad, un acuerdo reparatorio o incluso una terminación anticipada.

Recordemos, además, que en un proceso penal común existen dos jueces que participan a lo largo del proceso; el primero es el juez de la investigación preparatoria, que tiene como principal función dirigir la etapa intermedia. Y el segundo, que es el juez de juicio, quién se limitará a decidir y emitir sentencia. Pero como estamos frente a un proceso inmediato, el cual es distinto al proceso común, aquí no encontraremos una etapa intermedia, de tal forma que el juez de juicio oral, será el encargado de controlar el requerimiento de acusación y también evaluará si admito o no los medios probatorios (Arana, 2014).

Siguiendo los principios que recoge el Nuevo Código Procesal Penal, estamos frente a un nuevo sistema de corte garantista que -valga la redundancia- busca asegurar y garantizar los derechos del imputado frente a un proceso penal.

En un proceso inmediato, es innegable que no se vulnere las garantías procesales que posee el imputado, sobre todo cuando no se admita discutir los presupuestos materiales para la admisión de este proceso, como por el contrario si ocurriría en una acusación directa.

La acusación directa constituye un mecanismo mucho más garantista que el proceso inmediato, porque la acusación se somete a un control de acusación ante el juez de la investigación preparatoria y donde el imputado podrá ejercitar plenamente su derecho de defensa a través de todos los mecanismos previstos en el artículo 350 del NCPP, lo que no ocurre en el proceso inmediato, en el que no existe una etapa de control de acusación, sino que directamente el juez de juzgamiento emite el auto de enjuiciamiento y de citación a juicio (Arana, 2014, p. 277).

\section{Naturaleza Jurídica y Simplificación Procesal}

Como hemos podido desarrollar hasta aquí, en este nuevo proceso penal especial, el juez podrá emitir una sentencia en un lapso de tiempo breve, siempre y cuando estemos frente a una flagrancia delictiva bajo los 
supuestos que menciona el nuevo código procesal penal, en donde los trámites de su realización se han simplificado a los siguientes filtros:

- La recepción del informe de la Policía Nacional o el acta de realización de las diligencias preliminares con actos urgente e inaplazables.

- La solicitud del Ministerio Público de incoar un proceso inmediato.

- Aceptación del juez de la investigación preparatoria al pedido de la incoación de un proceso inmediato a solicitud del fiscal.

- Requerimiento de acusación por parte del Ministerio Público.

- El auto de enjuiciamiento con citación a juicio oral.

- La emisión de la sentencia.

Todos estos pasos se van a realizar de una manera oral, sin la necesidad de correr traslado de manera escrita, lo cual contribuye a la característica de celeridad procesal con la que cuenta este proceso especial.

Inferimos, entonces, que la idea del legislador consiste en alcanzar la competencia del sistema judicial para que pueda ofrecer una pronta solución a los conflictos que cumplan con los requisitos establecidos en el nuevo código procesal penal. De la misma manera, y quizás siguiendo los lineamientos del principio de economía procesal, se pretende racionalizar la carga laboral de todas las unidades jurisdiccionales, con el sentido de que sólo se admitan a juicio oral aquellos procesos que sean estrictamente necesarios en función al daño, la gravedad y la relevancia social que demanden.

Quizás en este punto la mayoría de nosotros podría llegar a pensar que la incoación de este proceso podría resultar favorable, en vista de que, en un proceso penal común, el plazo desde las diligencias preliminares hasta el juicio oral, puede llegar a ser de más de dos años, generando así una desconfianza en el sistema de tramitación judicial que el estado maneja. Pero, como bien menciona el profesor Peña Cabrera; la aplicación del proceso inmediato, si bien puede tener resultados ventajosos en la perspectiva sancionadora, no significa, necesariamente que sea producto del encauzamiento de este tipo de proceso especial, sino, muy por el contrario, de todas aquellas pésimas negociaciones por parte de la defensa en cuanto a acuerdos de terminación anticipada se trate[3].

Poniendo un claro ejemplo; si hablamos de delitos como el robo, el hurto agravado o la extorsión, podrían verse de una manera alentadora para el sistema de justicia, y sobre todo para la sociedad, puesto que tendríamos la sensación de que meter a la cárcel a personas como estas, es muy rápido en nuestro país. Pero si vamos un poco más allá, desde una perspectiva crítica; las personas que han cometido delitos de mediana gravedad, como, por ejemplo; la violencia contra un funcionario público en modalidad agravada[4] y terminen en un proceso inmediato, ¿en dónde encontramos los principios elementales del derecho penal democrático? Siguiendo a Angelino (2018), estaríamos frente a una situación inaceptable al momento de sujetar la labor del Ministerio Público a todas las -bisagras impenetrables- de la ley, intentando así, la armonización de su función con la independencia que la Constitución le otorga al momento de tomar las decisiones para la persecución criminal.

\section{Derecho a la Defensa y Plazo RAZONABLE}

De acuerdo al Tribunal Constitucional; el derecho a la defensa constituye un derecho fundamental que tiene una naturaleza procesal en la que engloba al debido proceso. Por ello, al momento de reconocerlo como un derecho fundamental, se convierte también como un principio de interdicción para las situaciones de indefensión. Empero, así como es un principio de interdicción, también es uno de contradicción para todos los actos procesales que recaen sobre alguna de las partes[5].

Si estamos frente a un proceso inmediato, como lo hemos visto en párrafos anteriores, ya no contamos con dos jueces que decidan sobre la responsabilidad penal del imputado, ya que ahora, es el mismo "juez de garantías" quien recoge todos los elementos de convicción y emite sentencia. 
Menciono esto, porque la idea del nuevo código al momento de poner dos jueces en un mismo proceso, es para evitar la contaminación del juez de juicio al momento de emitir sentencia, por ende, propone la participación de un juez de investigación preparatoria y un juez de juzgamiento. Ante ello, Salas (2011) refiere que no se puede entender ni suponer el valor del derecho a la defensa, si estamos frente a un juzgador que se encuentra "contaminado", ya sea de una manera consciente o inconscientemente con la idea de culpabilidad del procesado, producto de los elementos de convicción.

Otro aspecto importante a señalar, es el concerniente a la etapa intermedia, la cual tiene el objetivo principal de controla la acusación del fiscal, por ello veremos controles formales y sustanciales que la defensa solicita a esa misma acusación. Todo esto, con la finalidad de asegurar que la decisión del juez sea la más adecuada.

Tomando en cuenta el trabajo de Sabino (2018), la esencia del Nuevo Código Procesal Penal del 2004, aparte de ofrecer garantías al proceso, es también el de rescatar, en alguna medida, el respeto que debe alcanzarse sobre el plazo razonable, sobre todo cuando estamos en una etapa preparatoria, en donde la búsqueda de los actos urgentes e inaplazables consolidan las bases de una investigación que tiene la finalidad de ser veraz y legítimo.

Con la idea de reducción de etapas procesales que maneja el proceso inmediato, pasamos directamente de las diligencias preliminares hasta el juicio oral, sin contar con una formalización de investigación y tampoco con una etapa intermedia que se preste para controlar la acusación.

$\mathrm{Al}$ respecto, el problema no sólo radica en la pretensión que busca el fiscal sobre la sentencia, sino que, además, el problema también lo encontramos en la imposibilidad que tiene el abogado litigante al momento de estructurar la defensa del caso, ocasionando que muchas veces, como lo mencionamos líneas arriba, se busque una terminación anticipada de manera precipitada y diligente sin análisis, ni estudio previo.

No olvidemos que, para producir elementos de descargo, también se necesita un plazo prudencial que permita su elaboración. Con el toque imperativo del Decreto Legislativo No 1194, la incoación del proceso inmediato genera que la defensa no pueda incorporar elementos hasta la etapa de juzgamiento, ¿vulneración del derecho a la defensa?, quizás, pero si hablamos de la imposibilidad de la elaboración de una audiencia en que la se puedan presentar elementos de descargo; la defensa pierde el adjetivo eficaz.

De acuerdo con Nakazaki (2017) la defensa procesal no representa solamente un derecho subjetivo, ello es tan importante que, para la existencia del hombre con la sociedad, supera esa categoría. Incluso en la Teoría General del Derecho se le asigna la naturaleza jurídica de garantía. Por ende, el estado tiene la obligación de reconocerla formalmente y, a su vez, velar por su realidad efectiva durante el proceso.

Y todavía hay más.

Es una realidad innegable que la mayoría de procesos no llegan a afrontarse con un mismo defensor, el abogado litigante muchas veces tiene que tomar un caso que ya está en una etapa intermedia o peor aún, un caso que ya tiene fecha de juicio oral, acarreando consigo todas las ineficiencias que pudo haber cometido la defensa anterior. Entre todas esas dificultades, supongamos que el abogado de oficio no haya aportado argumentos de descargo y que el juez, a pesar de tener en cuenta que esos argumentos son relevantes para el estándar necesario, los ignore y admita el requerimiento del fiscal.

Lo mismo ocurriría con los supuestos legales de procedencia que hemos desarrollado párrafos atrás. Pensemos por un momento en que esos supuestos de procedencia hayan sido finalizados bajo una terminación anticipada; en donde no sólo falten actos de defensa, sino que, además, la información que brindó el Ministerio Público no es suficiente para que se acredite la existencia de todos los elementos constitutivos del tipo penal que estén utilizando para encerrar a una persona. Este es, a mi parecer, el problema más grande que genera la acusación fiscal en relación al derecho a la defensa en un proceso inmediato. (...) el deber del Estado de garantizar el derecho a contar con un defensor reconocido no se cumple con el simple nombramiento o designación de un abogado de oficio o de confianza, este tiene que asistir real e idóneamente al imputado en la causa penal (Nakazaki, 2017, pp. 479-480). 


\section{Conclusiones}

Después de desarrollar los antecedentes del proceso inmediato, su aplicación, su naturaleza y resolución procesal; menciono aquí algunos puntos a manera de conclusión:

- Los procesos especiales han estado presentes en la idea del legislador para reducir etapas y acelerar el proceso ordinario (o común). En el caso del proceso sumario, vendría a ser el antecesor del proceso inmediato, donde se fijaron bases para proponer una justicia rápida y efectiva. Sin embargo, la aplicación de este tipo de procesos especiales acarrea muchas dificultades que nuestro sistema judicial hoy en día afronta. Y si bien podría ofrecerse como una solución o sobre todo como una idea de confianza en nuestro sistema judicial, son justamente esas mismas deficiencias las que tendremos que pasar nosotros mismos a la hora de enfrentar un proceso contra el estado. Por ende, es necesario que nuestro sistema procesal respete y garantice el reconocimiento de todos nuestros derechos fundamentales.

- No cabe duda de que el proceso inmediato constituye un mecanismo procesal que representa y demuestra un tipo de justicia oportuna, el mismo que sólo deberá proceder frente a una evidencia delictiva, una flagrancia y los demás supuestos. Sin embargo, debe respetarse las reglas que son esenciales para garantizar el debido proceso, sobre todo cuando estemos frente a aspectos esenciales como la prueba, su origen, su legalidad y su validación. Es imperativo la presencia de una actividad probatoria para que se demuestre y exprese el sentido garantista que recoge el Nuevo Código Procesal Penal.

- La incoación de un proceso inmediato no depende sólo de supuestos legales de procedencia, sino también de presupuestos materiales que acrediten esa misma legalidad. Basta que demostremos la duda sobre alguna parte del requerimiento del proceso inmediato para que podamos debatir la improcedencia de este proceso y llevar el caso por la vía ordinaria, en donde sí podemos discutir todos los aspectos que, de ser el caso, pretendían ser olvidados por la fiscalía.

- En un estado democrático de derecho, el proceso penal no se puede convertir en una herramienta para llegar a la verdad a como dé lugar. Si bien esta premisa es lo que la sociedad espera del sistema de administración judicial, la búsqueda de esa verdad correspondería a varias interrogantes, entre ellas: ¿a qué tipo de verdad podemos llegar?, ¿nuestro sistema judicial está preparado para alcanzar algún tipo de verdad?, ¿o es que quizás esta discusión entraría a un plano filosófico en el cual nadie podría tener una verdad general? -Siguiendo a Peña Cabrera (2019) la única verdad en la que puede ser competente el sistema judicial, es la certeza, o sea, aquella afirmación que puede ser acreditada o probada. Esta reflexión representa la importancia del desarrollo de la actividad probatoria. No podemos llegar a condenar a una persona después de haber conseguido material probatorio que vulnere sus propios derechos fundamentales.

- Los elementos de convicción son aquellos datos objetivos que han sido incorporados a la investigación siguiendo procedimientos legales. No se puede admitir un elemento de convicción que no se haya ceñido a los procedimientos establecidos que están reconocidos en la propia norma adjetiva. Esas famosas "actas de reconocimiento inmediato" muchas veces no constituyen una investigación formal y legítima, sino, por el contrario, no son otra cosa que afirmaciones cargadas de subjetividad y sospecha que carecen de corroboración.

El proceso inmediato no significa que exista una sentencia a priori. El hecho de que la incoación pase el filtro y se determine la procedencia de una audiencia de juicio inmediato, no quiere decir que exista una condena. Como aspiración a una defensa eficaz, corresponde abandonar tal idea, si ya hubo notificación programando el juicio oral, no es necesario acudir a una terminación anticipada, aún se puede analizar los criterios de adecuación típica, todavía se puede demostrar que existe alguna causa de justificación, entre otros. Y lo más importante, analizar la legalidad del material probatorio que ha sido propuesto por el fiscal, pues aún se puede debatir, en escenarios determinados, siempre que resulten posibles. A pesar de que se carezca de recursos como el tiempo u otros, no se debe dar por terminado el proceso, ya que corresponde a una defensa eficaz que se absuelva al patrocinado. 


\section{Referencias Bibliográficas}

Arana, W. (2004). Manual de Derecho Procesal Penal para operadores jurídicos del nuevo sistema procesal penal acusatorio garantista. Lima, Perú: Gaceta Jurídica.

Araya, A. (2016). Nuevo proceso inmediato para delitos en flagrancia. Lima, Perú: Jurista Editores.

Angelino. J. (2018). El proceso inmediato como manifestación de simplificación procesal en el nuevo código procesal penal. En: IPEF, Revista Jurídica del Instituto Peruano de Estudios Forenses, Año XIV No 77.

Gaceta Penal (2010). Procedimientos Especiales, Lo nuevo del Código Procesal Penal del 2004 sobre los procedimientos especiales ( 4 ed.). Perú, Lima.: Editorial Gaceta Jurídica.

Nakazaki, C. (2017). El Derecho Penal y Procesal Penal desde la perspectiva del abogado penalista litigante. Lima, Perú: Gaceta Jurídica.

Peña Cabrera, A. (Ed.). (2017). El Proceso Inmediato como manifestación de simplificación procesal en el nuevo código procesal penal y su limitada actuación en el marco de la política criminal del derecho penal securitario. Lima, Perú: Pacífico Editores.

Peña Cabrera, A. (2009). El nuevo proceso penal peruano. Lima, Perú: Gaceta Jurídica.

Peña Cabrera, A. (2019). El Proceso Inmediato, Análisis sustantivo procesal y jurisdiccional. Lima, Perú: Pacífico Editores.

Sabino, M. (2018). El derecho de defensa en el proceso inmediato del nuevo código procesal penal del Perú dentro del marco regulatorio del decreto legislativo № 1194 (tesis de pregrado). Universidad Tecnológica del Perú, Lima, Perú. Extraído de: http://repositorio.utp.edu.pe/bitstream/UTP/2447/4/Manuel\%20Elera_Trabajo\%20de \%20Suficiencia\%20Profesional_Titulo\%20Profesional_2018.pdf Salas, C. (2011). El Proceso Penal Común. Lima, Perú: Gaceta Jurídica.

Salas, C. (2011). El Proceso Penal Común. Lima, Perú: Gaceta Jurídica.

Talavera, P. (2010). Breves apuntes sobre los procesos especiales en el nuevo código procesal penal (NCPP). Amag Perú, (9), 97-016.

Villegas, E. (2019). El Proceso Penal Acusatorio, Problemas y Soluciones. Lima, Perú: Gaceta Jurídica.

\section{JuRISPRUdENCIA, NormatividAD y OTROS DOCUMENTOS LEgALES}

Acuerdo Plenario Extraordinario No 2.2016/CIJ-116. Lima, Perú. 01 de junio de 2016. Recuperado de: https://img.lpderecho.pe/wp-content/uploads/2017/10/LEGIS.PE-Acuerdo-Plenario-002-2016-CJ-116Lesiones-y-faltas-por-da\%C3\%B1o-ps\%C3\%ADquico-y-afectaci\%C3\%B3n-psicol\%C3\%B3gica.pdf

Código de Procedimientos Penales (1940)

Constitución Política del Perú (1993)

Decreto Legislativo No 1194. Diario Oficial El Peruano, Lima, Perú, 30 de agosto de 2015. Recuperado de: https:// busquedas.elperuano.pe/normaslegales/decreto legislativo-que-regula-el-proceso-inmediato-en-casos-decretolegislativo-n 1194-1281034-2/

Directiva No 005-2016-MP-FN. Diario Oficial El Peruano, Lima, Perú, 08 de setiembre de 2016. Recuperado de: https://busquedas.elperuano.pe/normaslegales/aprueban-directiva-n-005- 2016-mp-fn-actuacion-del-fiscal-eresolucion-no-3939-2016-mp-fn-1427171-1/

Nuevo Código Procesal Penal (2004)

Tribunal Constitucional del Perú (2013). Sentencia recaída en el expediente No 07731-2013-PHC/TC. 9 de diciembre de 2015. Recuperada de: https://www.tc.gob.pe/jurisprudencia/2017/07731-2013-HC.pdf 
Rodrigo Guzman Arpasi. Entre el proceso inmediato y el derecho a la defensa eficaz: Garantías cons...

\section{Notas}

[1] Corte Suprema de Justicia de la República, II Pleno Jurisdiccional Extraordinario de las Salas Penales Permanente y Transitoria, Acuerdo Plenario Extraordinario No 2-2016/CIJ-116.

[2] Código Procesal Penal 2004

[3] Comentario extraído del artículo: "El Proceso Inmediato como manifestación de simplificación procesal en el NCPP y su limitada actuación en el marco de la política criminal del derecho penal securitario.

[4] Discriminando el marco penal imposible, en vista de que constituye una respuesta desproporcionada e irracional, según las últimas reformas en el Acuerdo Plenario No 1-2016/CJ-116

[5] STC. Exp. No 07731-2014 - PHC/TC, del 9 de diciembre del 2015, f. j. 4. 